\title{
Generosity of spirit sustains caseloading Lead Maternity Carer midwives in New Zealand
}

\author{
Marion Hunter ${ }^{A}, B$ DHSC Candidate, MA (Hons), BA, ADN, RM, RGON • Susan Crowther ${ }^{\mathrm{B} h D}, \mathrm{MSC}$, \\ BSC (Hons), RM, RN • Judith McAra-Couper ${ }^{B}$ PhD, BA, RM, RGON • Andrea Gilkison ${ }^{B}$ PhD, MEd, RM \\ - Debbie MacGregor ${ }^{B}$ MHPrac, RM • Jackie Gunn ${ }^{B}$ MA (Hons), ADN, RM, RGON
}

${ }^{\text {A Corresponding }}$ Author: mhunter@ aut.ac.nz

${ }^{\text {B } A u c k l a n d ~ U n i v e r s i t y ~}$ of Technology

${ }^{\mathrm{C}}$ Robert Gordon University, Aberdeen, Scotland

\begin{abstract}
:
Background: This article is the third in a series reporting on original research exploring the sustainability of Lead Maternity Carer (LMC) midwifery. Previous publications have described sustainable practice arrangements and the way that partnership and reciprocity with women sustain LMC midwives. Research about sustainable caseload practice is important because lessons can be learnt that ensure this model of care, with its excellent outcomes and high levels of maternal satisfaction, continues.
\end{abstract}

Aim: The aim of this paper is to provide stand-alone data in relation to what sustains LMC midwives in midwifery practice over time. The final theme to emerge from our original research arose from data which support the strong relationship between the midwives' generosity of spirit alongside professional boundaries that is critical to sustaining caseloading practice.

Method: A qualitative descriptive study was conducted in New Zealand. Eleven LMC midwives with between 8-20 years of practice experience were interviewed. Interviews were transcribed and the data thematically analysed. The researchers within the group undertook the analysis together in a reciprocal fashion between the individual interviews and all the data as a whole. Themes were clustered into groups and excerpts from the data used to illustrate the agreed themes. Ethics approval was obtained from Auckland University of Technology Ethics Committee.

Conclusion: This paper draws attention to the significance of generosity of spirit in LMC practice and how this acts synergistically with personal and professional boundaries. Reciprocity and partnership work well when generosity of spirt is enabled to flourish, and this, in turn, supports joy of practice. This paper provides further insight into how LMC practice is sustained over time and provides direction for midwives in LMC practice, and those planning to enter LMC practice, in New Zealand and elsewhere.

Keywords: Sustainability, generosity of spirit, caseload midwifery, midwife Lead Maternity Carer, midwifery practice

\section{INTRODUCTION}

This article is the third in the series and follows two previously published papers (Gilkison et al., 2015; McAra-Couper et al., 2014). The themes that were identified in the research and explored in those previous papers were: working in partnership, reciprocal supportive relationships, like-minded midwifery partners, realising one is not indispensable, practice arrangements and managing the unpredictability of being on call. In this paper, the final theme "generosity of spirit", describing the relationship between generosity of spirit and professional boundaries that sustain caseloading practice for Lead Maternity Carer (LMC) midwives, is explored.

New Zealand has a midwifery-led, primary maternity service where women choose their own LMC. LMC midwives are selfemployed practitioners who are contracted by the Ministry of Health (Ministry of Health, 2007). LMC midwives care for $93.4 \%$ of women, with the remainder choosing a general medical practitioner $(0.5 \%)$ or an obstetrician $(6 \%)$ (Ministry of Health, 2015). LMC midwives practise on their own responsibility and provide midwifery care for women in their community.
They have legal access to local maternity facilities, and consult and collaborate with professional colleagues if complications develop. LMC midwives provide continuity of midwifery care through pregnancy, labour and birth and up to six weeks postpartum. In this study, having a caseload means providing midwifery care throughout the childbirth continuum. This means that LMC midwives are on call for antenatal and postnatal concerns and for labour and birth care. To sustain this availability, LMC midwives usually belong to a practice group and/or have a practice partner, who provides backup and cover for time off.

Caseload LMC maternity care has been available in New Zealand for 25 years and been shown to be safe and acceptable. The majority of New Zealand women (90\%) are satisfied or very satisfied with LMC midwifery care (Ministry of Health, 2015) and perinatalrelated death rates continue to decrease. Overall, the perinataldeath rate is the lowest since the Perinatal and Maternal Mortality Review Committee began annual data collection in 2005 (Health Quality and Safety Commission New Zealand, 2007). There has also been a significant reduction in the rate of hypoxic peripartum perinatal-related deaths over recent years from $0.5 / 1000$ births in 2007 to $0.18 / 1000$ births in 2013 (Perinatal Maternal Mortality 
Review Committee, 2015). These significant positive outcomes add to the argument for sustaining the community-based, caseload LMC midwifery-led model of maternity care.

Our research found that generosity of spirit is part of the history and culture of New Zealand midwifery and is integral to the sustainability of LMC midwifery practice (Guilliland \& Pairman, 1995, 2010). As Leap, Dahlan, Brodie, Tracy, \& Thorpe (2011) said, generosity of spirit is a way of being that builds positive relationships not only with women, but between midwives. Generosity of spirit includes trust, feeling connected, goodwill, and the ability to take care of oneself (which leaves room for generosity of spirit). Henry (2015) proposes a difference between generosity and generosity of spirit. Henry asserts that generosity refers to something we do, whereas generosity of spirit refers to something we are. Seeking ways of practice that nurture generosity of spirit requires development of realistic boundaries in practice that both nurture generosity of spirit and vice versa. This is the meaning of generosity of spirit in this study and, we maintain, is at the heart of the culture that sustains LMC midwives in New Zealand.

\section{Literature review}

Midwifery-led, continuity of care models of care have been shown to have significant benefits, including higher rates of spontaneous vaginal birth, less intrapartum analgesia or anaesthesia and women being less likely to experience regional analgesia, episiotomy and instrumental birth (National Health Service, 2014; Sandall, Devane, Soltani, Hatem, \& Gates, 2010). Furthermore, a metaanalysis found that the majority of studies reviewed also reported a higher rate of maternal satisfaction in a midwifery-led continuity care model (Sandall, Soltani, Gates, Shennan, \& Devane, 2013). This aligns with the experience of most women in New Zealand who express satisfaction with the LMC (continuity of care caseload) model of care (Ministry of Health, 2015).

For midwives, providing continuity of care for women is a satisfying way to work, and contributes to sustainable practice (Collins, Fereday, Pincombe, Oster, \& Turnbull, 2010; Edmondson \& Walker, 2014; Sandall et al., 2013). Sustainability is defined as enabling "something to continue to exist, whilst maintaining the integrity of mental and physical well-being of the agent" (McAraCouper et al., 2014, p. 29). In the context of this study, sustainable midwifery is defined as a way of practising which will ensure that the LMC model of care will be maintained, whilst maintaining the integrity of the mental and physical well-being of the midwife.

Relationships with women appear to be one of the most important aspects of sustainability of midwifery practice (Deery \& Hunter, 2010; Hunter, 2006; Hunter, Berg, Lundgren, Ólafsdóttir, \& Kirkham, 2008; Leap et al., 2011). Hunter (2006) refers to the reciprocal nature of the midwife-woman relationship, and suggests that this reciprocity contributes to the emotional well-being of midwives, thereby sustaining the midwife in practice.

Whilst benefits for caseloading midwifery are clear in terms of benefits for women and midwives, there has been recent research which focused on the challenges that may arise for midwives who are caseloading and providing continuity of care. These difficulties relate to the very real challenges of being on call, maintaining a healthy work-life balance, and burnout (Cox \& Smythe, 2011; Donald, Smythe, \& McAra-Couper, 2014; Sandall, 1997; Young, Smythe, \& McAra-Couper, 2015). These studies offer important insights into the experience and sometimes career-ending challenges for some caseloading midwives. However, other LMC midwives appear to manage the challenges they encounter and sustain LMC practice for many years.
Given the importance of sustaining a model of care with clearly identified benefits, our research investigated what does sustain midwives who have worked in the LMC model of midwifery care for more than eight years within the New Zealand context.

\section{METHOD}

Human inquiry is always within a complex living system (Wadsworth, 2011). LMC practice is such a living system. Therefore, a qualitative research approach was adopted as it affords the opportunity for exploring the complexities that are inherent within this living system. Qualitative descriptive methodology, informed by Sandelowski (2010), was used so that complex detailed descriptions of how and what sustains LMC midwives in practice could be uncovered. A qualitative descriptive approach allows the voices of participants to be central to analysis. Subsequent findings therefore remain near to participant descriptions of practice.

Ethical approval for this study was obtained through the Auckland University of Technology Ethics Committee (AUTEC) in 2011.

The research design consisted of interviews with eleven LMC midwives in 2011 and 2012. They needed to have been in LMC practice for at least eight years, and participants were from a variety of rural and urban regions throughout New Zealand. Recruitment was through purposive sampling and the researchers' professional networks were used initially to ensure participants met the inclusion criteria. They were contacted by email, phone or in person and given information sheets about the study. Midwives self-selected as participants, and other midwives meeting the criteria for the study were additionally recruited through a snowballing technique. None of the participants worked together as practice partners at the time of data collection.

When prospective participants indicated they wished to participate, a convenient time and place for a face-to-face interview was organised. Semi-structured interviews using openended questions provided opportunity for descriptions about what sustains, and does not sustain, practice, for example: "What sustains you in midwifery practice? Tell me about how that sustains your practice?" The interviews took approximately 4590 minutes, were audiotaped and transcribed. Transcripts were returned to participants when requested and for clarification when required. Pseudonyms were assigned and details were changed to ensure participant confidentiality.

A team approach to analysis was employed and provided opportunities to ensure plausibility of themes as they emerged from the data. The research team individually read, analysed and coded all the transcripts which were then returned to the whole group for peer review and comment. The peer review of the ongoing analysis ensured trustworthiness in the process and subsequent findings. As analysis progressed, relationships and patterns, across participant descriptions and between identified themes, surfaced. Themes and sub-themes were constantly refined in team discussions until consensus was achieved. The emergence of coalescing patterns across varying practice descriptions revealed the "what" and "how" of long-term sustainable LMC practice. Processes such as these ensure trustworthiness, which is essential in qualitative methodologies (Rolfe, 2006).

\section{FINDINGS \\ Generosity of spirit}

One of the themes which emerged from the research was termed "generosity of spirit". Generosity of spirit is often described using words that are associated with ways of being, such as: magnanimity, high mindedness, fairness and generousness. As Dreyfus (2011) puts it, generosity of spirit is a kind of open-heartedness. Midwives 
in this study spoke of having a spirit of open-heartedness between practice partners and colleagues, which sustained them in LMC practice. Generosity of spirit revealed itself in midwifery practice in myriad ways. Iona gives an example of how generosity of spirit between LMC midwifery partners sustains her in practice:

It's about generosity towards your midwifery partner...
thoughtfulness and consideration for the other person's
caseload. I do think the thing that gives you longevity in
LMC practice is good will. Good will and generosity, not
greed. I think you have to really have a generous spirit.
That means in all ways, time, money, energy, the whole lot;
generosity to be tolerant of variations and difference. I'd
say that's the most critical element; generosity needs to be
inherent in your soul otherwise it won't work. (Iona)

Iona speaks about the generosity of spirit in many ways, both on a practical level as well as an emotional level between midwifery partners, as the single most important ingredient sustaining this relationship, and thereby sustaining LMC practice.

This spirit of generosity can be picked up by others as Carla states:

\begin{abstract}
One of the stories... amongst midwives who are not part of our practice, is that "those midwives look after each other really well"... That's what enables us to keep going, because we do often arrive in the hospital with food or just kind of say, "look, go lie down for an hour and I'll help out"... so people have a perception of us as a group that look after each other. (Carla)
\end{abstract}

Generosity of spirit in Carla's LMC group practice is clearly seen by the wider midwifery community. This reciprocity and mutual support have also been shown elsewhere as key to positive working arrangements (Kirkham, 2011). Midwives positively supporting midwives generates generosity of spirit and reciprocity.

At times this generosity of spirit is shown in both practical and moral support when one midwife is feeling vulnerable, in this case after a significant event:

And one of the other midwives from the [practice] came as
well, and sat outside the door. And every time I freaked out
that this young woman was probably going to die, 'cause
that's what I thought everyone was going to do for a while,
I'd just go outside and talk to her and get back in there and
she had a baby and all was well. So that was kind of the
beginning of getting my confidence back... To midwife me
back into being able to be a midwife. (Andrea)

Andrea describes how she was "midwifed" back into midwifery practice after a major clinical episode through the generous spirit of her practice partners. Andrea's story describes how generosity of spirit, reciprocity and appreciation of each other's needs bolstered her ability to maintain healthy functional relationships with women, throughout her own period of vulnerability. For this practice, generosity of spirit was not a formal arrangement, yet it was the generosity of philosophically aligned practice partners which supported Andrea to continue in practice.

Generosity of spirit between midwifery partners and colleagues lays the foundation for healthy partnership with women. Carla continues sharing about her practice:

[Lack of generosity] doesn't grow us as healthy midwives who care for each other... and also that's what we're doing for women, so if you're not doing the model to each other as midwives and forming partnerships and relationships how are you doing it... with women? I don't believe you are. I believe if you can't do it with each other and have that generosity and give each other your time... and that's what gives the generosity back... that's what makes it work. (Carla)

For Carla, having a generosity of spirit between midwives will keep her and her colleagues healthy. LMC practice cannot be sustained unless LMCs are physically and mentally healthy. Having generous relationships with colleagues is one way to maintain your personal well-being. LMC midwives in this study also talk of the generosity of spirit conveyed by the wider midwifery community. Sheila describes her experience:

I took a month off [after a major clinical event]. The midwives supported me amazingly. Someone from the practice came with me to every birth for as long as I needed it. The support was amazing. The support from the wider midwifery community was also great. I had midwives that I barely knew... you know...core midwives from the hospital - just come up to me and hug me and just amazing support. Midwives just know - midwives, that have been around a long time anyway - know what it must be like. (Sheila)

The data in this New Zealand study show the power and influence of generous behaviours and their impact and contribution towards sustainability. Jones (2000) contends that "as long as this circle of empowerment remains unbroken, it is self-perpetuating" (p.167). However, generosity of spirit is something that needs to be worked at, in order to flourish. Generosity of spirit needs to evolve in the culture of sustainable LMC midwifery practice. For some of the study's midwives it was inherent and part of who they are, yet this quality developed with time and experience. Several participants in this study indicated that they "arrived" at an understanding of the meaning of generosity of spirit in a variety of ways. At times this awareness came from a pivotal experience in practice that caused an "epiphany of understanding", or occasionally by maturation of practice, or by joining a like-minded group of midwives who embodied generosity of spirit. What is revealed in these LMCs' stories is how generosity of spirit and sustainable practice are entwined.

\section{The data in this New Zealand study show the power and influence of generous behaviours and their impact and contribution towards sustainability.}

Occasionally, being away from work for a substantial amount of time gives LMC midwives an opportunity to reflect on and re-evaluate the way they need work to sustain their health and well-being that in turn sustains their ability to remain generous of spirit. Karen's "epiphany of understanding" came when she returned to work after she had been off sick for several months:

I was back on deck for the last couple weeks of her postnatal care and when I signed her off I said, "Oh, I'm really sorry I wasn't there for the birth". And she said, "Oh that was fine, the other midwife was really good". And I thought, all these years, I've put my life on hold to be available for these women and actually to them it's possibly not as important as it has been to me. So, that was the turning point for me. I thought really I've got to start thinking that health 
and family are more important than being on call, no matter what. (Karen)

Karen states that for many years she had "put her life on hold to be available" for her clients because her perception had been that this was crucial to them. After apologising for not being at the woman's birth, Karen realised that she was not indispensable after all. Being overly generous with time and being always available to her clients can risk putting the midwife's health and family second. Establishing boundaries, which facilitate working in partnership and providing quality of care, needs to incorporate the paramount need to look after one's self.

Holly alludes to a previous way of working and the impact on her family's well-being when she was "giving everything" to her midwifery practice. At times new LMC midwives may over extend themselves in terms of availability to their clients:

\section{I probably showed them a model that was too balanced towards just giving everything. I mean, that sounds silly really, but not enough work-life balance in terms of time off and healthy activities to diffuse the stress... (I wish I had had) real time off and done more things with the family and showed them that there was life where the phone wasn't always there and the possibility of mum always having to rush away. I think the way I worked just stemmed from when I started. (Holly)}

One of the dangers of "over-generous" behaviours is the harming of self, by overextending. Saying "yes" to every request, which may be seen as being over-generous, can lead to lack of self-care and poor work-life balance. Although midwives are sustained by partnership and reciprocal relationships with women, they also need to negotiate and communicate boundaries and ensure their professional and personal lives are integrated in a balanced way.

\section{Negotiating Boundaries}

For the midwives to remain generous of spirit, certain strategies are required to support and sustain this quality. These strategies appear to be around negotiating and maintaining professional boundaries that support generosity of spirit, and invariably come as an evolution of practice. Diana illustrates this in describing how her practice arrangements have evolved over time:

\section{After 10 years of feeling guilty for everything that I didn't do and every text that I told off or every phone call that I didn't answer.... [then] that guilt actually went away, it did go away, when I made my choices and made my boundaries clearer to me... I had a shift in practice, asking women to ring in business hours versus around the clock. (Diana)}

For Diana the joy of practice was overshadowed by guilt; she expresses guilt for everything she didn't do. When the need for boundaries became clearer she was able to practise in a way that was sustainable. Diana learnt to be generous to herself by letting go of guilt and having clearer boundary setting. Boundaries (both personal and professional) are essential for maintaining a generosity of spirit that sustains midwifery practice. Self-care supports a healthy work-life balance and is essential to sustainability (Donald et al., 2014). Self-care is supported when midwives establish a workable set of expectations in their professional relationships with women as well as in their dealings with their midwifery partners.

Jane explains the need to be very clear about appropriate contact methods in an era of text messaging:

I think texting is potentially very dangerous for the woman and us as practitioners...so unless it's something like changing appointments...something completely nonurgent... where if the midwife doesn't pick up that text for three days it's not going to matter. But we really highlight and put in bold and then highlight again on top. 'Please Do Not Text-This is not safe care for you or your baby.' And then we state the urgent 24-hour contact reasons such as the usual stuff about bleeding, abdominal cramps, preeclampsia signs and symptoms, baby is not moving, signs of labour. Those sorts of 24-hour contact details - we spell them out literally - and then...then each of the midwives is free to let the women know how she can be contacted in a non-urgent way. (Jane)

Providing clear details of these expectations around what are accepted and safe behaviours ensures boundaries are respected, and generosity of spirit in partnerships is maintained for both midwives and women. Jane and her practice partners explain that texting might not be safe; they give detailed information as to when women need to ring the midwife 24/7, as opposed to non-urgent contact. Ways of working together are built upon generosity of spirit, but strategies need to be employed to sustain the generosity of spirit that, in turn, sustains LMC practice. Another example is provided by Beatrice:

I also ensure that my clients know that my text sounds are never on, my text sounds are always on silent, because I feel very protective of my space with the women. (Beatrice)

Guarding "space" would seem crucial if practice is to be sustainable. The protected space is an opportunity to focus on the woman that Beatrice is caring for at the time. Yet this protection of space is also how Beatrice maintains boundaries around her work to ensure she has space for herself. Helen illustrates once again the significance of maintaining boundaries in her practice:

... and I AM freely available, when I need to be, but not for changing an appointment at 11 o'clock at night and so there was a bit of a conversation about that. (Helen)

While Helen states she is freely available 24/7 for her clients, she expects "out of hours" contact to be of an urgent nature. Helen will have a conversation with a woman if needed so there is clarity of expectations regarding contacting the midwife for urgent and non-urgent matters. Midwives in this study said it was important to share with women the arrangements for having regular time off. Georgia shares how her practice created boundaries between work life and personal life, through having regular time off:

Women know when I am available. We write that in our booklet. For non-urgent queries, they can phone 8 am-5pm weekdays, so we're quite protective of our free time and they completely respect that and understand that when we talk that through. I think it's all about how we present it to them. Our relationship is very respectful of them and respectful of us, really. And they completely get it. I try to take about one long holiday, have every second weekend off from $5 \mathrm{pm}$ Friday to $8 \mathrm{am}$ Monday... and that's brilliant. (Georgia)

Having clarity between the woman and the midwife about time off and when it is appropriate to contact the midwife, creates a mutually agreed boundary and meets the midwife's need for protected time off work. More than that, it creates a respectful relationship between the woman and the midwife which will ensure a functioning partnership. Clear boundaries and facilitating reciprocal generosity of spirit are not mutually exclusive between women and their midwives. 
Generosity of spirit is crucial if the joy of practice reported in our previous papers is to be maintained and to sustain midwives working in continuity of care models. As Brenda explains:

Enjoy it. It can be such fun. It can be such an amazing
job. And take time out. Don't be too available. Keep
your boundaries. Boundaries, boundaries, boundaries.
Boundaries are very important, because it can eat you up
really, this job. Can't it? I LOVE my work. I LOVE my
practice. I LOVE the women I work with. I think that's
hugely sustaining. I love working with a supportive group
of midwives... I can't even imagine what it would be like
working in isolation... we have a lot of fun. (Brenda)

Brenda describes her joy of midwifery practice and how she is mindful of her boundaries. She encourages midwives to enjoy LMC practice as it can be fun and an "amazing job". Her advice is to take time out and not be overly available. Brenda also encourages LMCs to enjoy their colleagues and not work in isolation, reiterating the significance of meaningful midwifery relationships in terms of underpinning sound partnerships with women and attuning practice to a generosity of spirit.

\section{DISCUSSION}

For midwives in this study, generosity of spirit between colleagues was one of the things which sustained them in their practice. Nurturing positive collegial relationships through practical and emotional support enabled midwives to continue to build effective partnerships with women. Midwives spoke of the importance of nurturing an ethos of collective caring, and building positive relationships with women and with one another, which sustained them in LMC practice.

The unpredictable nature of LMC midwifery practice calls for a manageable way of maintaining one's professional and personal life. Midwives in our research talked about boundaries in their practice alongside the generosity of spirit as the two things that set the foundation for a working partnership through the journey of childbirth. Whilst midwives are inspired and nurtured by partnership and reciprocal relationships, and give their best to women-centred care (Leap et al., 2011), they also need to ensure their professional and personal lives are integrated in a balanced and sustainable way. Midwives need to be able to care for themselves and each other, in order to care for women.

The findings reveal that being overly generous and without boundaries often results in midwives losing the "joy of practice" and, conversely, when we lack generosity with self, colleagues and clients, the "joy of practice" can also be diminished. As Henry (2015) puts it, cynicism and despair create a "corrosive threat to generosity of spirit" (p.16). When midwives do not have good professional and personal boundaries, the joy of practice is threatened and this can result in an erosion of their generosity of spirit, and potentially lead to burnout. Awareness of the need for boundaries, primarily the need to look after oneself, at the start of a midwife's career is of the utmost importance. Responding to excessive client demand in the belief it is "good care" is a misconstrued interpretation of the partnership model and is unsustainable.

Yet, boundaries are not something that just happen but often need to be put in place formally with clear communication about practice expectations. The balancing of generosity of spirit and boundaries is nowhere more clearly seen than in caseload midwife practice arrangements. Being clear about practice arrangements provides the foundation for well-functioning sustainable relationships (Gilkison et al., 2015), ensuring boundaries are respected and generosity of spirit in the partnership is maintained. When boundary setting is balanced, and boundaries are meaningfully explained, women are able to accept the need for their LMC midwife to have structured time off and that the backup midwife will provide care at these times.

\section{Awareness of the need for boundaries, primarily the need to look after oneself, at the start of a midwife's career is of the utmost importance. Responding to excessive client demand in the belief it is "good care" is a misconstrued interpretation of the partnership model and is unsustainable.}

Hunter (2006) believes that this balanced exchange of generosity, or "give and take" between midwives and women, is emotionally rewarding and sustainable for the midwife. Coincidently and fortuitously, it usually leads to enhanced quality of care being received by the woman. Reciprocity has been described by Berg, Ólafsdóttir, and Lundgren (2012) as an affirmation that encompasses availability and participation by both parties in order to build trust. In the first article in this series, midwives identified that "the primary factor that sustains them is the joy experienced in the reciprocal relationship formed when LMC midwives work in partnership with women and their families/whānau" (McAraCouper et al., 2014, p. 32). Jones (2000) also suggests that midwives' generosity of spirit, reciprocity and an empowering culture create support for each other.

Generosity of spirit and professional boundaries are different sides of the same coin that is LMC midwifery practice. Brown (2015) claims that generosity cannot exist without boundaries and "boundaried" people can be the most compassionate and empathetic. There is a subtle reframing of generosity of spirit so that it now includes boundaries. This is no longer viewed as limiting or restricting but rather as empowering. These two aspects of practice are complementary, not mutually exclusive. The findings of this research reveal how both aspects must be functioning well for practice to flourish.

\section{STRENGTHS AND LIMITATIONS}

This study has explored aspects of New Zealand LMC practice previously not researched and has revealed elements which can now be further researched. These include more nuanced exploration of generosity of spirit and professional boundaries, practices that successfully sustain LMC case-loading midwifery and external personal and professional networks that sustain each midwife. Although these findings are not generalisable to all midwives in New Zealand or to all regions in the world, the findings might be transferable to other settings and countries seeking to sustain caseload continuity of carer models.

\section{CONCLUSION}

Professional and personal boundaries work in synergy with a generosity of spirit, providing the foundation for sustainable LMC midwifery practice. When midwives approach their work-life association with magnanimity and fairness, generosity of spirit is 
enmeshed in their practice. This spirit disseminates to like-minded colleagues and toward clients. The midwives in our research provided insight into the generosity of spirit that underpins their practice and their professional relationships, along with how they establish and negotiate boundaries which are integral to their worklife balance. They described the various strategies they employ to establish and maintain boundaries in relation to sustaining on call, such as: information and expectations of urgent versus nonurgent concerns, time off and guidance as to how to contact the midwife on call. The foundation of sustainable caseload practice is generosity of spirit which permeates all midwifery interactions with others. The strength of this foundation is nourished by a supportive framework that safeguards personal and professional boundaries. This requires midwives to work in partnership with women and colleagues in a way that enhances reciprocal respect and appreciation of each other's roles. This study shows that when generosity of spirit goes hand in hand with boundaries, only then can the health and well-being of the midwife be nurtured and be sustained.

\section{ACKNOWLEDGMENTS AND CONFLICT OF INTEREST STATEMENT}

The authors wish to acknowledge and thank the midwives who participated in this study.

All authors have declared there are no conflicts of interest.

\section{REFERENCES}

Berg, M., Ólafsdóttir, Ó. A., \& Lundgren, I. (2012). A midwifery model of woman-centred childbirth care - In Swedish and Icelandic settings. Sexual \& Reproductive Healthcare, 3(2), 79-87. doi:10.1016/j. srhc.2012.03.001

Brown, B. (2015). Daring Greatly: How the Courage to Be Vulnerable Transforms the Way We Live, Love, Parent, and Lead. New York: Avery.

Collins, C. T., Fereday, J., Pincombe, J., Oster, C., \& Turnbull, D. (2010). An evaluation of the satisfaction of midwives' working in midwifery group practice. Midwifery, 26(4), 435-441. doi:10.1016/j. midw.2008.09.004

Cox, P., \& Smythe, L. (2011). Experiences of midwives' leaving Lead Maternity Care (LMC) practice. New Zealand College of Midwives Journal 44, 17-21.

Deery, R., \& Hunter, B. (2010). Emotional work and relationships in midwifery. In M. Kirkham (Ed.), The midwife-mother relationship (2nd ed.). Basingstoke: Palgrave Macmillan.

Donald, H., Smythe, L., \& McAra-Couper, J. (2014). Creating a better work-life balance. New Zealand College of Midwives Journal, 49, 5-10.

Dreyfus, E. A. (2011). Living Life from the Inside Out: Who You Are Matters. U.S.A: Createspace.

Edmondson, M. C., \& Walker, S. B. (2014). Working in caseload midwifery care: The experience of midwives working in a birth centre in North Queensland. Women \& Birth, 27(1), 31-36. doi:10.1016/j. wombi.2013.09.003

Gilkison, A., McAra-Couper, J., Gunn, J., Crowther, S., Hunter, M., Macgregor, D., \& Hotchin, C. (2015). Midwifery practice arrangements which sustain caseloading Lead Maternity Carer midwives in New Zealand. New Zealand College of Midwives Journal 51, 11-16. doi:10.12784/nzcomjnl51.2015.2.11-16

Guilliland, K., \& Pairman, S. (1995). The midwifery partnership: a model for practice (Vol. 95/1). Wellington, New Zealand: Department of Nursing and Midwifery, Victoria University of Wellington.

Guilliland, K., \& Pairman, S. (2010). The Midwifery Partnership, A Model for Practice (2nd ed.). Christchurch, New Zealand: New Zealand College of Midwives.

Health Quality and Safety Commission New Zealand. (2007). Perinatal and Maternal Mortality Review Committee: First Report to the Minister of Health: June 2005 to June 2007. Wellington. Retrieved from http:// www.hqsc.govt.nz/our-programmes/mrc/pmmrc/publications-andresources/publication/26
Henry, D. V. (2015). Generosity of spirit. Retrieved from http://www. baylor.edu/content/services/document.php/253573.pdf

Hunter, B. (2006). The importance of reciprocity in relationships between community-based midwives and mothers. Midwifery, 22(4), 308-322. doi:10.1016/j.midw.2005.11.002

Hunter, B., Berg, M., Lundgren, I., Ólafsdóttir, Ó. A., \& Kirkham, M. (2008). Relationships: the hidden threads in the tapestry of maternity care. Midwifery, 24(2), 132-137.

Jones, O. (2000). Supervision in a midwife managed birth centre. In M. Kirkham (Ed.), Developments in the supervision of midwives. Manchester: Books for Midwives.

Kirkham, M. (2011). Sustained by joy: The potential of flow experience for midwives and mothers. In L. Davies, R. Daellenbach, \& M. Kensington (Eds.), Sustainability, Midwifery and Birth. Oxon, United States: Routledge.

Leap, N., Dahlan, H., Brodie, P., Tracy, S., \& Thorpe, J. (2011). Relationships - the glue that holds it all together: Midwifery continuity of care and sustainability. In L. Davies, R. Daellenbach, \& M. Kensington (Eds.), Sustainability, Midwifery and Birth. Oxon, United States: Routledge.

McAra-Couper, J., Gilkison, A., Crowther, S., Hunter, M., Hotchin, C., \& Gunn, J. (2014). Partnership and reciprocity with women sustain Lead Maternity Carer midwives in practice. New Zealand College of Midwives Journal, 49, 29-33.

Ministry of Health. (2007). Primary maternity services notice 2007: NZ Government. Retrieved from http://www.moh.govt.nz/moh. nsf/pagesmh/5845/\$File/s88-primary-maternity-services-noticegazetted-2007.doc

Ministry of Health. (2015). Maternity Consumer Survey 2014. Wellington: Research New Zealand. Retrieved from https://www.health. govt.nz/publication/maternity-consumer-survey-2014

National Health Service. (2014). One to one quality account April 2013-March 2014. U.K. National Health Service.

Perinatal Maternal Mortality Review Committee. (2015). Ninth Annual Report of the Perinatal and Maternal Mortality Review Committee: Reporting mortality 2013. Wellington. Retrieved from http://www.hqsc. govt.nz/assets/PMMRC/Publications/Ninth-PMMRC-report-FINALJun-2015.pdf

Rolfe, G. (2006). Validity, trustworthiness and rigour: quality and the idea of qualitative research. Journal of Advanced Nursing, 53(3), 304-310.

Sandall, J. (1997). Midwives' burnout and continuity of care. British Journal of Midwifery, 5(2), 106-111.

Sandall, J., Devane, D., Soltani, H., Hatem, M., \& Gates, S. (2010). Improving quality and safety in maternity care: the contribution of midwife-led care. Journal of Midwifery \& Women's Health, 55(3), 255 261. doi:10.1016/j.jmwh.2010.02.002

Sandall, J., Soltani, H., Gates, S., Shennan, A., \& Devane, D. (2013). Midwife-led continuity models versus other models of care for childbearing women. Cochrane Database of Systematic Reviews. doi:10.1002/14651858.CD004667.pub3

Sandelowski, M. (2010). What's in a name? Qualitative description revisited. Research in Nursing \& Health, 33(1), 77-84. doi:10.1002/ nur.20362

Wadsworth, Y. (2011). Do it yourself social research: the bestselling practical guide to doing social research projects (3rd ed.). Walnut Creek, CA Left Coast Press.

Young, C. M., Smythe, L., \& McAra-Couper, J. (2015). Burnout: Lessons From the Lived Experience of Case Loading Midwives. International Journal of Childbirth, 5(3), 154-165.

\section{Accepted for publication October 2016}

Hunter, M., Crowther, S., McAra-Couper, J., Gilkison, A., MacGregor, D., \& Gunn, J. (2016). Generosity of spirit sustains caseloading Lead Maternity Carer midwives in New Zealand. New Zealand College of Midwives Journal, 52, 50-55

http://dx.doi.org/10.12784/nzcomin152.2016.8.50-55 